\title{
PENGARUH MOTIVASI KERJA DALAM MEMEDIASI PENGARUH PENGEMBANGAN KARIR TERHADAP KINERJA
}

\author{
Ni Komang Sisi Sania Natalia ${ }^{1}$ \\ I Gusti Salit Ketut Netra ${ }^{2}$ \\ ${ }^{1,2}$ Fakultas Ekonomi dan Bisnis Universitas Udayana (Unud), Bali, Indonesia \\ email: sisisania25@gmail.com
}

\begin{abstract}
ABSTRAK
Penelitian ini bertujuan untuk mengetahui peran motivasi kerja dalam memediasi pengaruh pengembangan karir terhadap kinerja karyawan. Penelitian ini dilakukan di Single Fin Surf Shop, Cafe and Bar Kabupaten Badung. Jumlah sampel yang diambil sebanyak 106 orang karyawan, dengan metode sampel jenuh. Pengumpulan data diperoleh dari hasil penyebaran kuesioner. Analisis data, analisis jalur, analisis sobel dan analisis VAF. Hasil penelitian ini ditemukan bahwa pengembangan karir berpengaruh positif dan signifikan terhadap motivasi kerja karyawan. Pengembangan karir berpengaruh positif dan signifikan terhadap kinerja karyawan. Motivasi kerja berpengaruh positif dan signifikan dalam memediasi pengaruh antara pengembangan karir terhadap kinerja karyawan. Single Fin Surf Shop, Cafe and Bar Kabupaten Badung sebaiknya memberikan kesempatan karir yang berkaitan dengan pendidikan untuk melaksanakan pekerjaan sehingga karyawan dapat menghasilkan kinerja yang maksimal serta memberikan motivasi kepada karyawan agar dapat mengembangkan karirnya.
\end{abstract}

Kata Kunci : kinerja karyawan, motivasi kerja, pengembangan karir

\begin{abstract}
This study aims to determine the role of work motivation in mediating the effect of career development on employee performance. This research was conducted at the Single Fin Surf Shop, Cafe and Bar Badung Regency. The number of samples taken was 106 employees, using the saturated sample method. Data collection was obtained from the results of questionnaires. Data analysis, path analysis, single analysis and VAF analysis. The results of this study found that career development had a positive and significant effect on employee work motivation. Career development has a positive and significant effect on employee performance. Work motivation has a positive and significant effect in mediating the influence between career development on employee performance. Bad Fin Single Shop, Cafe and Bar Badung Regency should provide career opportunities related to education to carry out work so that employees can produce maximum performance and provide motivation for employees to develop their careers.
\end{abstract}

Keywords: employee performance, work motivation, career development 


\section{PENDAHULUAN}

Sumber daya manusia (SDM) di era globalisasi saat ini dapat dikatakan sebagai faktor utama yang memegang peranan penting untuk meraih keberhasilan suatu perusahaan. Sebuah perusahaan dapat menjadi berkembang dan maju tentunya tidak hanya dari faktor permodalan dan strategi bisnis yang kuat, melainkan SDM yang hebat. Sumber daya manusia (SDM) yang dimaksud adalah para karyawan atau pekerja. Persaingan dalam dunia kerja yang semakin ketat menuntut perusahaan untuk terus meningkatkan kinerja karyawan sehingga dapat mencapai tujuan perusahaan yang akan mendatangkan profit (keuntungan). Perusahaan dapat mencapai hasil atau target yang diinginkan sesuai dengan visi dan misi perusahaan diperlukan semangat, usaha, dan kinerja yang benar-benar kuat dari pekerja dan jajaran manajemen di dalamnya.

Budianto dan Katini (2015) mengungkapkan kinerja merupakan perilaku nyata yang ditampilkan setiap orang sebagai prestasi kerja yang dihasilkan oleh pegawai sesuai dengan perannya dalam instansi. Kinerja karyawan diartikan sebagai pencapaian tugas, dimana karyawan dalam bekerja harus sesuai dengan program kerja organisasi untuk mencapai visi, misi, dan tujuan organisasi (Hakim, 2014). Seorang karyawan dikatakan berhasil melaksanakan pekerjaannya atau memiliki kinerja baik, apabila hasil kerja yang diperoleh lebih tinggi dari standar kinerja. Penilaian kinerja menjadi alat yang dapat membantu karyawan dan perusahaan mencapai tujuannya. Menurut Kaymz (2011) penilaian kinerja berfungsi sebagai alat komunikasi bagi karyawan dalam melihat hasil kerja, apakah targetnya tercapai atau tidak sehingga mempengaruhi kesuksesan karirnya.

Oduma et al. (2014) menyatakan bahwa seorang pimpinan yang mengharapkan pencapaian kinerja maksimal di organisasinya harus memperhatikan faktor-faktor yang mempengaruhi kinerja pegawai itu sendiri, salah satunya adalah pengembangan karir (career development). Menurut Kudsi et al. (2017) pengembangan karir adalah suatu usaha yang dilakukan oleh karyawan dalam meningkatkan kinerjanya dan dilakukan secara terus menerus untuk mendapatkan apresiasi kenaikan jenjang jabatan yang diberikan perusahaan. Cederyana \& Supriyati (2018) pengembangan karir adalah suatu langkah yang bisa digunakan perusahaan demi menjaga dan menaikkan produktivitas karyawan dan untuk mempersiapkan karir masa depan seorang karyawan. Pratiwi (2017) menyatakan perusahaan juga diharapkan lebih memberikan pengembangan karir dengan memperhatikan peluang untuk melakukan promosi dan perlunya mentor untuk bimbingan informal, sehingga karyawan dapat menguasai pekerjaan yang mereka miliki sesuai dengan tanggung jawab yang didapat. Karyawan agar dapat bertahan lama, perusahaan juga menyediakan peluang karir bagi setiap karyawan.

Le Tran dan Chiou-shu (2015) menjelaskan bahwa kinerja karyawan dipengaruhi oleh motivasi. Menurut Omolo (2015) penyebab kinerja pegawai yang rendah adalah motivasi yang disebabkan oleh penyimpangan oleh pegawai, tingginya biaya perekrutan, pelatihan, meningkatnya persaingan, peningkatan regulasi oleh pemerintah serta adanya perasaan hilangnya motivasi dan terlalu banyak bekerja. Menurut Kuranchie \& Tawiah (2016) motivasi dapat menginspirasi orang untuk bekerja secara individu atau dalam kelompok sedemikian rupa untuk menghasilkan hasil terbaik. Theodoran (2015) menyatakan bahwa seorang 
karyawan yang termotivasi akan bersifat energik dan bersemangat, dan sebaliknya seorang karyawan dengan motivasi yang rendah akan sering menampilkan rasa tidak nyaman dan tidak senang terhadap pekerjannya yang mengkibatkan kinerja mereka menjadi buruk dan tujuan perusahaan tidak tercapai.

Penelitian ini dilaksanakan di Single Fin Surf Shop, Cafe and Bar Kabupaten Badung yang merupakan perusahaan yang bergerak dibidang jasa, makanan, minuman, dan surf shop. Single Fin Surf Shop, Cafe and Bar yang berlokasi di Jalan Labuan Sait, Pantai Suluban, Kecamatan Kuta Selatan, Kabupaten Badung, Bali mulai beroperasi pada bulan Maret 2011. Single Fin menjadi salah satu tempat persinggahan para wisatawan lokal maupun mancanegara karena memiliki pemandangan yang sangat indah serta saat berkunjung dapat menikmati musik live yang ditampilkan oleh DJ tamu internasional dan band-band lokal ternama. Sampai saat ini Single Fin tergolong cafe terbuka yang banyak dikunjungi oleh para wisatawan lokal maupun mancanegara, untuk itu perusahaan dituntut untuk selalu menjaga dan meningkatkan kualitas kerja karyawan agar mampu bersaing dengan cafe-cafe lainnya.

Berdasarkan hasil wawancara dengan HRD yang dilakukan masih terdapat bahwa karyawan memiliki kinerja yang kurang maksimal dapat dilihat pada Tabel 1. sebagai berikut.

Tabel 1.

Data Target Penjualan pada Sinlge Fin Surf Shop, Cafe and Bar Kabupaten Badung Tahun 2019

\begin{tabular}{llllll}
\hline No & Bulan & Target & Realisasi & Selisih & $\begin{array}{c}\text { Pesentase } \\
(\boldsymbol{\%})\end{array}$ \\
\hline 1 & Januari & 6.435 .271 .700 & 5.874 .333 .511 & 560.938 .189 & 8.72 \\
2 & Februari & 5.902 .417 .162 & 5.800 .211 .340 & 102.205 .822 & 1.73 \\
3 & Maret & 5.834 .568 .900 & 5.100 .347 .252 & 734.221 .648 & 12.58 \\
4 & April & 6.889 .312 .751 & 6.881 .118 .934 & 8.193 .817 & 0.12 \\
5 & Mei & 6.895 .450 .900 & 6.771 .301 .875 & 124.149 .025 & 1.80 \\
6 & Juni & 7.002 .318 .607 & 6.993 .241 .300 & 9.077 .307 & 0.13 \\
7 & Juli & 8.581 .335 .423 & 8.605 .110 .720 & -23.775 .297 & -0.28 \\
8 & Agustus & 9.292 .871 .333 & 9.271 .412 .350 & 21.458 .983 & 0.23 \\
9 & September & 9.117 .447 .812 & 8.993 .091 .213 & 124.356 .599 & 1.36 \\
10 & Oktober & 8.567 .912 .560 & 8.381 .740 .921 & 186.171 .639 & 2.17 \\
11 & November & 8.075 .891 .445 & 7.748 .510 .944 & 327.380 .501 & 4.05 \\
12 & Desember & 7.931 .441 .892 & 7.518 .904 .221 & 412.537 .671 & 5.20 \\
Total & & $\mathbf{9 0 . 5 2 6 . 2 4 0 . 4 8}$ & $\mathbf{8 7 . 9 3 9 . 3 2 4 . 5 8 1}$ & $\mathbf{2 . 5 8 6 . 9 1 5 . 9 0 4}$ & $\mathbf{3 8}$ \\
PerTahun & & & & & \\
Rata-rata & & $\mathbf{7 . 5 4 3 . 8 5 3 . 3 7 4}$ & $\mathbf{7 . 3 2 8 . 2 7 7 . 0 4 8}$ & $\mathbf{2 1 5 . 5 7 6 . 3 2 3}$ & $\mathbf{3 8}$ \\
\hline
\end{tabular}

Sumber: Single Fin Surf Shop Cafe and Bar Kabupaten Badung, 2019 
Tabel 1. menunjukkan bahwa jumlah ralisasi Single Fin Surf Shop, Cafe and Bar mengalami fluktuasi jumlah naik atau turun, dimana realisasi penjualan Single Fin Surf Shop, Café and Bar Kabupaten Badung hanya bulan juli mampu mencapai target yang ditetapkan perusahaan. Semua penjualan pasti akan mengahadapi berbagai kendala dalam meningkatkan penjualan. Hal ini disebabkan oleh persaingan yang semakin ketat disamping itu wisatawan juga memiliki karakteristik dan budaya berbeda. Untuk menunjang kelancaran perusahaan maka karyawan berperan penting dalam proses interaksi wisatawan dengan mengutamakan keramah tamahan serta mengutamakan keinginan wisatawan dengan tujuan wisatawan merasa puas dengan pelayanan yang diterima saat berkunjung ke Single Fin Surf Shop, Cafe and Bar.

Pengembangan karir tentu menjadi suatu hal yang diinginkan oleh setiap karyawan karena umumnya semakin baik sebuah jabatan, maka semakin sejahtera juga kehidupan karyawan. Berdasarkan hasil wawancara dengan beberapa karyawan bahwa karyawan merasa kurang adil mengenai pengembangan karir. Hal yang menjadi dasar pengembangan karir bagi seorang karyawan yaitu kenaikkan jabatan yang dilakukan oleh atasan pada masing-masing bagian. Pendidikan yang dimiliki oleh karyawan, dimana atasan lebih sering mengutamakan kepada karyawan yang mempunyai tingkat pendidikan lebih tinggi (Diploma dan Sarjana) dibandingkan pegawai yang masih berpendidikan SMA untuk menduduki posisi. Hal ini diketahui meskipun seorang karyawan tersebut adalah karyawan tetap sudah bekerja lama tetapi latar belakang pendidikannya tidak sesuai dengan kriteria pengembangan karir, maka tetap saja karyawan tersebut tidak dapat mengikuti atau mendapat kesempatan pengembangan karir. Dalam hal ini sebaiknya pihak atasan memberikan kesempatan karir kepada karyawan yang hanya lulusan SMA dengan tujuan karyawan bisa mengembangkan karir sesuai dengan keahlian yang dimiliki.

Karyawan yang motivasinya rendah cenderung melalaikan pekerjaan salah satunya karyawan dalam bentuk ketidakhadiran yang tinggi dan juga karyawan yang bekerja kurang maksimal. Hasil wawancara dengan HRD mengemukakan bahwa motivasi karyawan di Single Fin Surf Shop Cafe and Bar masih cenderung rendah, beberapa karyawan diketahui telah melanggar peraturan yang di tetapkan perusahaan. Salah satu cara yang di lakukan pihak manajemen agar karyawan mampu bekerja lebih maksimal dengan mengadakan pengajian bulanan bersama seluruh karyawan Single Fin Surf Shop Cafe and Bar rutin setiap hari kamis sebulan dua kali dengan hal itu karyawan akan lebih termotivasi sehingga tidak lagi terjadi pelanggaran yang dilakukan oleh karyawan.

Menurut Shahzadi et al. (2014) kinerja karyawan melibatkan kualitas dan kuantitas output, kehadiran ditempat kerja dan ketepatan waktu dalam menyelesaikan tugas. Suatu pekerjaan memiliki persyaratan tertentu untuk dapat dilakukan dalam mencapai tujuan yang biasanya disebut sebagai standar pekerjaan (job standard). Permasalahan kinerja karyawan diduga disebabkan oleh faktor pengembangan karir dan motivasi kerja yang terbilang rendah. Hal ini didukung oleh penelitian yang dilakukan Elqadri et al. (2015) dan Nurcahyani \& Adnyani (2016) yang mengatakan bahwa kinerja karyawan dipengaruhi oleh motivasi, sedangkan Baroroh (2012) mengatakan kinerja karyawan dipengaruhi oleh pengembangan karir. 
Penelitian terdahulu yang dilakukan Putri (2019) menyatakan bahwa pengembangan karir mimiliki pengaruh positif dan signifikan terhadap motivasi kerja. Penelitian yang dilakukan Umar (2015) dan Susilo dkk. (2018) menyatakan bahwa pengembangan karir berperngaruh positif dan signifikan terhadap motivasi kerja yang artinya pengembangan karir yang jelas akan memberikan motivasi yang tinggi.

Penelitian yang dilakukan oleh Nkechi dan Dialoke (2017) menyatakan bahwa pengembangan karir berpengaruh positif dan signifikan terhadap kinerja karyawan. Sari (2016) menyatakan bahwa pengembangan karir berpengaruh terhadap kinerja karyawan. Sebagaimana dibuktikan dalam hasil penelitian terdahulu bahwa pengembangan karir menjadi kesuksesan karyawan dan kinerja karyawan akan meningkat. Penelitian yang dilakukan oleh Muogbo (2013) menyatakan bahwa pemberian motivasi bagi para pekerja dalam suatu organisasi dapat berpengaruh dengan signifikan terhadap kinerja karyawan. Pegawai yang senang dengan pekerjaannya mengindikasikan loyalitas dan semangat kerja yang tinggi. Motivasi dan kinerja karyawan adalah alat penting untuk mencapai kesuksesan dalam organisasi.

Penelitian yang dilakukan oleh Zameer \& Shehzad (2014) menemukan bahwa peran motivasi kerja sangat vital untuk meningkatkan kinerja karyawan. Dapat disimpulkan bahwa motivasi sangat vital dalam meningkatkan kinerja karyawan, dengan adanya motivasi dari atasan maka karyawan akan merasa puas terhadap pekerjaannya.Penelitian yang dilakukan Dewi dan Utama (2016) menjelaskan yang dapat membantu meningkatkan motivasi kerja adalah dengan pengembangan karir yang baik, ketika motivasi kerja karyawan tinggi dalam perusahaan maka kinerja karyawan akan meningkat. Sehingga dapat dikatakan motivasi kerja memediasi hubungan pengembangan karir terhadap kinerja karyawan.

Hal tersebut di dukung oleh penelitian yang dilakukan Charity (2015) menyatakan pengembangan karir yang dikelola dengan baik oleh perusahaan akan memberikan semangat yang baik bagi karyawannya untuk mencapai karir yang mereka harapkan serta dapat meningkatkan motivasi kerja karyawan. Dengan kata lain, semakin baik pengembangan karir dan motivasi kerja diperusahaan tertentu, maka akan semakin baik pula kinerja karyawan di perusahaan.

Penelitian yang dilakukan oleh Mahmud et al. (2018) menyatakan bahwa pengembangan karir memiliki pengaruh positif dan signifikan terhadap motivasi kerja. Penelitian yang dilakukan oleh Lisdiani \& Ngatno (2017) menyatakan bahwa pengembangan karir berpengaruh signifikan terhadap motivasi kerja, artinya dengan adanya pengembangan karir yang baik maka karyawan akan merasa termotivasi sehingga menciptakan rasa puas dalam melaksanakan pekerjaan. Dengan adanya program pengembangan karir, dapat lebih meningkatkan dorongan atau motivasi kepada karyawan untuk lebih berprestasi dan memberikan kontribusi yang maksimal kepada perusahaan. Hasil penelitian yang dilakukan oleh Hannekam (2016) mengemukkan pengembangan karir memiliki pengaruh positif yang signifikan terhadap motivasi kerja karyawan.

Penelitian yang dilakukan oleh Bapiri \& Alizad (2015) menyatakan bahwa career development berpengaruh positif dan signifikan terhadap motivasi kerja karyawan di Sepah Bank. Penelitian yang dilakukan oleh (Supranowo, 2017) 
menyatakan bahwa pengembangan karir berpengaruh positif dan signifikan terhadap motivasi kerja artinya bahwa motivasi karyawan akan meningkat dengan adanya pengembangan karir yang baik. Pillay (2015) bahwa pengembangan karir berpengaruh positif terhadap motivasi karyawan. Hal ini berarti semakin baik pengembangan karir maka akan semakin tinggi motivasi kerja karyawan. Hasil penelitian Anthony \& Weide (2015) mendapatkan hasil bahwa pengembangan karir berpengaruh terhadap motivasi karyawan. Berdasarkan hal tersebut hipotesis yang dapat dikembangkan dalam penelitian ini adalah:

$\mathrm{H}_{1}$ : Pengembangan karir berpengaruh positif dan signifikan terhadap motivasi kerja karyawan.

Penelitian yang dilakukan oleh Nasution et al. (2018) menyatakan bahwa pengembangan karir berpengaruh terhadap kinerja karyawan. Purwanto dkk. (2017) menunjukkan pengembangan karir berpengaruh signifikan terhadap kinerja karyawan artinya apabila pihak manajemen mampu meningkatkan perencanaan karir maka diharapkan dapat meningkatkan efisiensi perusahaan dalam memperoleh tingkat kinerja yang maksimal, selain itu untuk mengontrol karir pegawai agar tidak terjadi kesalahan yang berdampak negatif terhadap perusahaan. Perencanaan karir juga diharapkan dapat menimbulkan semangat kompetisi yang efektif agar karyawan lebih bersemangat lagi.

Penelitian yang dilakukan oleh Rosmadi (2018) menyatakan bahwa pengembangan karir memiliki pengaruh yang signifikan terhadap kinerja karyawan. Hal ini didukung oleh Kurniawan et al. (2017) menyatakan bahwa pengembangan karir berpengaruh positif dan signifikan terhadap kerja karyawan. Charity (2015) menunjukkan bahwa pengembangan karir berpengaruh signifikan terhadap kinerja karyawan yang menunjukkan bahwa penting bagi perusahaan atau lembaga yang beroperasi di perbankan untuk fokus pada peningkatan pengembangan karir di perusahaan sehingga kinerja karyawannya dapat meningkat.

Penelitian Parerung (2014) juga menunjukkan bahwa pengembangan karir berpengaruh terhadap kinerja karyawan. Hal ini menunjukkan dengan adanya pengembangan karir, karyawan merasa adanya kepastian dalam karir yang akan diraih dimasa yang akan datang, sehingga diimbangi dengan memberikan kinerja yang optimal. Napitupulu (2017) menyatakan bahwa pengembangan karir berpengaruh positif terhadap kinerja karyawan. Hal ini menyatakan bahwa semakin baik pengembangan karir maka semakin baik kinerja karyawan. Berdasarkan hal tersebut hipotesis yang dapat dikembangkan dalam penelitian ini adalah:

$\mathrm{H}_{2}$ : Pengembangan karir berpengaruh positif dan signifikan terhadap kinerja karyawan.

Penelitian yang dilakukan oleh Larasati \& Gilang (2014) menyatakan motivasi kerja memiliki pengaruh positif dan signifikan terhadap kinerja karyawan. Penelitian ini juga didukung oleh Ayundasari et al. (2017) menyatakan bahwa motivasi kerja berpengaruh positif signifikan terhadap kinerja karyawan. Oleh karena itu, adanya dukungan motivasi dari atasan maka seorang karyawan akan memiliki motivasi yang tinggi untuk terus melakukan pekerjaan diperusahaan dengan baik. Theodoran (2015) menyatakan bahwa motivasi kerja berpengaruh positif terhadap kinerja karyawan. 
Hasil yang sama diperoleh dari penelitian yang dilakukan oleh Ibrahim (2017) bahwa motivasi karyawan berepengaruh postif terhadap kinerja karyawan. Maka dapat dinyatakan bahwa semakin tinggi motivasi karyawan maka semakin baik kinerja karyawan, dan begitu pula sebaliknya. Penelitian yang dilakukan oleh Bismantara (2017) menyatakan bahwa motivasi secara parsial berpengaruh signifikan terhadap kinerja karyawan dikarenakan adanya motivasi dapat mendorong karyawan untuk berkinerja tinggi.

Dengan adanya pemberian motivasi baik motivasi positif maupun motivasi negatif kepada karyawan dapat mendorong karyawan lebih giat bekerja sehingga kinerja karyawan dapat ditingkatkan. Berdasarkan hal tersebut hipotesis yang dapat dikembangkan dalam penelitian ini adalah:

$\mathrm{H}_{3}$ : Pengaruh motivasi berpengaruh positif dan signifikan terhadap kinerja karyawan.

Penelitian yang dilakukan oleh Dewi \& Utama (2016) menyatakan pengembangan karir dan motivasi berpengaruh positif dan signifikan terhadap kinerja karyawan. Umar (2015) mengemukkan bahwa motivasi kerja memediasi pengaruh pengembangan karir terhadap kinerja karyawan. Oduma et al., (2014) menyatakan pengembangan karir berpengaruh positif terhadap kinerja karyawan. Kualitas pengembangan karir karyawan sangat berpengaruh pada kinerja. Hal ini dapat terjadi karena semakin baik pengembangan karir karyawan, semakin tinggi kinerja karyawan tersebut.

Balbed dan Sintaasih (2019) membuktikan bahwa motivasi kerja mampu memediasi pengaruh pengembangan karir terhadap kinerja karyawan. Kinerja karyawan dapat ditingkatkan dengan menjaga ataupun meningkatkan pengembangan karir dan motivasi kerja karyawan. Sari dan Sriathi (2019) menunjukkan bahwa menyatakan motivasi kerja berpengaruh positif terhadap kinerja karyawan serta mampu memediasi pengaruh pengembangan karir terhadap kinerja karyawan.

Hasil ini menyatakan bahwa semakin baik pengembangan karir diperusahaan semakin tinggi motivasi kerja karyawan, dan semakin tinggi motivasi kerja karyawan akan semakin tinggi kinerja karyawan.Berdasarkan hasil penelitian, hipotesis yang dapat diajukan dalam penelitian ini adalah:

$\mathrm{H}_{4}$ : Motivasi kerja berpengaruh positif dan signifikan dalam memediasi hubungan antara pengembangan karir terhadap kinerja karyawan.

\section{METODE PENELITIAN}

Lokasi penelitian ini dilakukan di Single Fin Surf Shop, Cafe and Bar Kabupaten Badung, yang beralamat di Pantai Suluban, Jl. Labuan Sait, Pecatu, Kecamatan Kuta Selatan, Kabupaten Badung. Lokasi ini dipilih karena terdapat masalah mengenai kinerja karyawan yang kurang maksimal dalam bekerja.

Populasi dalam penelitian ini adalah seluruh karyawan Single Fin Surf Shop, Cafe and Bar Kabupaten Badung yang berjumlah 106 orang. Metode yang digunakan adalah sampel jenuh, dimana seluruh anggota populasi digunakan sebagai sampel. Jadi keseluruhan karyawan yang bekerja di Single Fin Surf Shop, Cafe and Bar Kabupaten Badung sebesar 106 orang. Pada Tabel 2 akan ditunjukan 
jumlah karyawan Single Fin Surf Shop, Cafe and Bar Kabupaten Badung sebagai berikut:

Tabel 2.

Jumlah Karyawan Single Fin Surf Shop, Cafe and Bar Kabupaten Badung Tahun 2018

\begin{tabular}{ccc}
\hline No & Departemen & Banyak Karyawan (orang) \\
\hline 1 & General Manager & 1 \\
2 & Sale Marketing & 5 \\
3 & Human Resource & 2 \\
4 & Accounting & 7 \\
5 & F\&B Service & 38 \\
6 & Hostess & 5 \\
7 & Kitchen & 21 \\
8 & Engineering & 11 \\
9 & Security & 5 \\
10 & Cleaning Service & 9 \\
11 & Graphic Designer & 2 \\
Total & & 106 \\
\hline
\end{tabular}

Sumber: Single Fin Surf Shop, Cafe and Bar Kabupaten Badung, 2018

Teknik analisis data dalam penelitian ini menggunakan teknik analisis jalur (path analysis).

Persamaan Sub-struktural 1

$$
\mathrm{Z}=\beta 1 \mathrm{X}+\mathrm{e}
$$

Persamaan Sub-struktural 2

$$
\begin{aligned}
& \mathrm{Y}=\beta 1 \mathrm{X}+\beta 2 \mathrm{Y} 1+\mathrm{e} \\
& \text { Keterangan: } \\
& \mathrm{Y} \quad=\text { kinerja karyawan } \\
& \mathrm{X}=\text { pengembangan karir } \\
& \beta 1, \beta 2=\text { koefisien regresi variabel } \\
& \mathrm{e}=\text { error }
\end{aligned}
$$

\section{HASIL DAN PEMBAHASAN}

Pada penelitian ini dihitung pengaruh pengembangan karir terhadap motivasi kerja melalui program SPSS 21.0 for windows. Berikut ini ditampilkan hasil perhitungan struktur pertama pada Tabel 3.

Berdasarkan hasil analisis jalur pada Tabel 3 maka dapat dirumuskan persamaan struktural yang terbentuk adalah sebagai berikut.

$$
\begin{gathered}
Z=\beta_{1} X+e_{1} \\
Z=0,606 X+e 1
\end{gathered}
$$

Variabel pengembangan karir memiliki koefisien sebesar 0,606 berarti pengembangan karir memiliki pengaruh positif terhadap motivasi kerja, ini diartikan apabila pengembangan karir baik maka motivasi kerja akan meningkat sebesar 0,606. 
Tabel 3.

Hasil Analisis Jalur Pada Struktur 1

\begin{tabular}{|c|c|c|c|c|c|}
\hline \multirow[t]{2}{*}{ Model } & \multicolumn{2}{|c|}{ Unstandardized Coefficients } & \multirow{2}{*}{$\begin{array}{c}\text { Standardized } \\
\text { Coefficients } \\
\text { Beta }\end{array}$} & \multirow[t]{2}{*}{$\mathbf{T}$} & \multirow[t]{2}{*}{ Sig. } \\
\hline & B & Std. Error & & & \\
\hline (Constant) & 0.978 & 0.329 & & 2.973 & 0.004 \\
\hline $\begin{array}{l}\text { Pengembangan Karir } \\
\mathrm{R}^{2}\end{array}$ & 0.709 & 0.091 & 0.606 & 7.762 & 0.000 \\
\hline
\end{tabular}

Sumber: Data diolah, 2019

Pada penelitian ini dihitung pengaruh pengembangan karir dan motivasi kerja terhadap kinerja karyawan melalui program SPSS 21.0 for windows. Berikut ini ditampilkan hasil perhitungan struktur kedua pada Tabel 4.

Tabel 4.

Hasil Analisis Jalur Pada Struktur 2

\begin{tabular}{lccccc}
\hline \multirow{2}{*}{ Model } & \multicolumn{2}{c}{$\begin{array}{c}\text { Unstandardized } \\
\text { Coefficients }\end{array}$} & $\begin{array}{c}\text { Standardized } \\
\text { Coefficients }\end{array}$ & T & Sig. \\
\cline { 2 - 4 } & B & Std. Error & Beta & & \\
\hline (Constant) & 0.180 & 0.272 & & 0.663 & 0.509 \\
Pengembangan Karir & 0.400 & 0.091 & 0.333 & 4.395 & 0.000 \\
Motivasi Kerja & 0.557 & 0.078 & 0.543 & 7.162 & 0.000 \\
$\mathrm{R}^{2}: 0.625$ & & & & & \\
\hline
\end{tabular}

Sumber: Data diolah, 2019

Berdasarkan hasil analisis jalur pada Tabel 4 maka dapat dirumuskan persamaan struktural yang terbentuk adalah sebagai berikut:

$$
\begin{aligned}
& Y=\beta_{2} X+\beta_{3} Z+e_{2} \\
& Y=0,333 X+0,543 Z+e 2
\end{aligned}
$$

Variabel pengembangan karir memiliki koefisien sebesar 0,333 berarti pengembangan karir memiliki pengaruh positif terhadap kinerja karyawan, ini diartikan apabila pengembangan karir baik maka kinerja karyawan akan meningkat sebesar 0,333. Variabel motivasi kerja memiliki koefisien sebesar 0,543 berarti motivasi kerja memiliki pengaruh positif terhadap kinerja karyawan ini diartikan apabila tinggi motivasi kerja maka kinerja karyawan akan meningkat sebesar 0,543.

Pada penelitian ini pengujian normalitas dilakukan menggunakan analisis grafik histogram, normal probability plot dan analisis statistik One-Sample Kolmogorov-Smirnov, yaitu dengan membandingkan Kolmogorov-Smirnov hitung dengan Kolmogorov-Smirnov. Adapun hasil uji One-Sample Kolmogorov-Smirnov dapat ditampilkan dalam Tabel 5.

Berdasarkan uji normalitas dengan menggunakan One-Sample KolmogorovSmirnov Test yang ditampilkan pada Tabel 5. tersebut menunjukkan bahwa besarnya nilai Kolmogorov-Smirnov adalah sebesar 0,503 dan 0,316. Nilai Kolmogorov-Smirnov tersebut lebih besar dibandingkan dengan nilai Kolmogorov- 
Smirnov tabel sebesar 0,05 maka $\mathrm{H}_{\mathrm{o}}$ diterima yang mengindikasikan bahwa data yang digunakan pada penelitian ini terdistribusi normal, sehingga dapat disimpulkan bahwa model memenuhi asumsi normalitas.

Tabel 5.

Uji Normalitas (One-Sample Kolmogorov-Smirnov)

\begin{tabular}{cl}
\hline Persamaan & Kolmogorov-Smirnov Z \\
\hline Substruktur 1 & 0,503 \\
Substruktur 2 & 0,316
\end{tabular}

Sumber: Data diolah, 2019

Uji multikolinearitas dilakukan untuk melihat apakah terdapat korelasi yang sempurna antar variabel bebas yang digunakan pada penelitian ini. Pengujian multikolinearitas dilakukan dengan menganalisis nilai tolerance dan nilai VIF. Nilai tolerance dan nilai VIF digunakan untuk mengukur variabilitas variabel independen atau hubungan antar variabel independen, jika nilai tolerance kurang dari 0,10 atau nilai VIF lebih dari 10 maka menunjukkan adanya multikolinearitas. Adapun nilai tolerance dan nilai VIF ditunjukkan pada Tabel 6. berikut:

Tabel 6.

Uji Multikolinieritas (Tolerance dan Variance Inflation Factor)

\begin{tabular}{llcc}
\hline \multirow{2}{*}{ Model } & \multicolumn{2}{c}{ Collinearity Statistics } \\
\cline { 2 - 3 } & & Tolerance & VIF \\
\hline \multirow{2}{*}{ Substruktur2 } & Pengembangan Karir & 0.633 & 1.579 \\
& Motivasi Kerja & 0.633 & 1.579 \\
\hline
\end{tabular}

Sumber: Data diolah, 2019

Tabel 6. tersebut ditunjukkan bahwa tidak terdapat variabel bebas yang memiliki nilai tolerance kurang dari 0,10 dan juga tidak ada variabel bebas yang memiliki nilai VIF lebih dari 10. Maka dari pada itu model regresi bebas dari gejala multikoleniaritas.

Tabel 7.

Uji Heteroskedastisitas (Uji Glesjer) Coefficients(a)

\begin{tabular}{clcc}
\hline Persamaan & \multicolumn{1}{c}{ Model } & T & Sig. \\
\hline Substruktur1 & Pengembangan Karir & -1.661 & 0.100 \\
& & 0.376 & 0.708 \\
Substruktur 2 & Pengembangan Karir & -1.681 & 0.096 \\
\hline
\end{tabular}

Sumber: Data diolah, 2019

Pengujian heteroskedastisitas diakukan melalui metode glesjer. Metode glesjer meregresikan model regresi untuk mendapatkan nilai residualnya, kemudian nilai residual tersebut diabsolutkan dan dilakukan regresi dengan semua variabel independen. Bila terdapat variabel independen yang berpengaruh secara signifikan terhadap residual absolut maka terjadi heteroskedastisitas pada model regresi ini.

Berdasarkan Tabel tersebut, ditunjukkan bahwa masing-masing model memiliki nilai signifikansi lebih besar dari 5 persen. Hal ini menunjukkan bahwa variabel bebas yang digunakan pada penelitian ini tidak berpengaruh secara 
signifikan terhadap variabel terikatnya yaitu absolute error, maka dari itu, penelitian ini bebas dari gejala heteroskedastisitas.

Berdasarkan hasil pada Tabel 3. pengembangan karir memiliki nilai Beta sebesar 0,606 dan nilai Sig. sebesar 0,000, maka dapat dikatakan $\mathrm{H}_{a}$ diterima karena nilai Sig. 0,000<0,05. Kesimpulannya adalah bahwa pengembangan karir memiliki pengaruh positif dan signifikan terhadap motivasi kerja, dengan kata lain semakin baik pengembangan karir pada Single Fin Surf Shop, Cafe and Bar, maka semakin meningkat motivasi kerja Single Fin Surf Shop, Cafe and Bar Kabupaten Badung, sehingga hipotesis pertama diterima.

Berdasarkan hasil pada Tabel 4. pengembangan karir memiliki nilai Beta sebesar 0,333 dan nilai Sig. sebesar 0,000, maka dapat dikatakan $\mathrm{H}_{\mathrm{a}}$ diterima karena nilai Sig. 0,000<0,05. Kesimpulannya adalah pengembangan karir berpengaruh positif dan signifikan terhadap kinerja karyawan dengan kata lain semakin baik pengembangan karir maka kinerja karyawan Single Fin Surf Shop, Cafe and Bar Kabupaten Badung akan semakin baik, sehingga hipotesis kedua diterima.

Berdasarkan hasil pada Tabel 4. motivasi kerja memiliki nilai Beta sebesar 0,543 dan nilai Sig. sebesar 0.000, maka dapat dikatakan $\mathrm{H}_{\mathrm{a}}$ diterima karena nilai Sig. $0.000<0,05$. Kesimpulannya adalah bahwa motivasi kerja memiliki pengaruh positif dan signifikan terhadap kinerja karyawan, dengan kata lain apabila motivasi kerja karyawan tinggi maka kinerja karyawan Single Fin Surf Shop, Cafe and Bar Kabupaten Badung akan semakin meningkat, sehingga hipotesis ketiga diterima.

Uji sobel merupakan alat analisis untuk menguji signifikansi dari hubungan tidak langsung antara variabel independen dengan variabel dependen yang dimediasi oleh variabel mediator. Uji Sobel dirumuskan dengan persamaan berikut dan dapat dihitung dengan menggunakan aplikasi Microsoft Excel 2010. Bila nilai kalkulasi Z lebih besar dari 1,96 (dengan tingkat kepercayaan 95 persen), maka variabel mediator dinilai secara signifikan memediasi hubungan antara variabel terikat dan variabel bebas.

$$
\mathrm{Z}=\frac{\mathrm{ab}}{\sqrt{\mathrm{b}^{2} \mathrm{~S}_{\mathrm{a}}^{2}+\mathrm{a}^{2} \mathrm{~S}_{\mathrm{b}}^{2}+\mathrm{S}_{\mathrm{a}}^{2} \mathrm{~S}_{\mathrm{b}}^{2}}}
$$

Keterangan :

$$
\begin{aligned}
& a=0,606 \\
& S_{a}=0,091 \\
& b=0,543 \\
& S_{b}=0,078
\end{aligned}
$$

Sumber: Baron and Kenny (1986)

$$
\begin{aligned}
Z & =\frac{0,606.0,543}{\sqrt{\left(0,543^{2} 0,091^{2}\right)+\left(0,606^{2} 0,078^{2}\right)+\left(0,091^{2} 0,078^{2}\right)}} \\
Z & =\frac{0,329}{0,069} \\
Z & =4,759
\end{aligned}
$$


Berdasarkan hasil Uji Sobel menunjukkan bahwa hasil tabulasi $\mathrm{Z}=$ 4,759>1,96 yang berarti variabel pengembangan karir berpengaruh positif dan signifikan terhadap kinerja karyawan Single Fin Surf Shop, Cafe and Bar Kabupaten Badung dengan mediasi motivasi kerja, sehingga motivasi Kerja merupakan variabel mediasi pengaruh antara pengembangan karir terhadap kinerja karyawan Single Fin Surf Shop, Cafe and Bar Kabupaten Badung, Sehingga hipotesis keempat diterima.

Pada pengujian ini akan dilihat nilai masing-masing koefisien determinasi untuk struktur 1 dan struktur 2 serta nilai masing-masing variabel error pada setiap struktur dengan tujuan penyusunan model diagram jalur akhir. Berikut ini hasil perhitungan nilai variabel error pada setiap struktur.

$$
\begin{aligned}
& \mathrm{e}_{\mathrm{i}}=\sqrt{1-\mathrm{R}_{\mathrm{I}}^{2}} \ldots \ldots \ldots \ldots \ldots \ldots \ldots \ldots \ldots \ldots \ldots \ldots \\
& \mathrm{e}_{1}=\sqrt{1-R_{1}^{2}}=\sqrt{1-0,367}=0,796 \\
& \mathrm{e}_{2}=\sqrt{1-R_{2}^{2}}=\sqrt{1-0,625}=0,612
\end{aligned}
$$

Pada perhitungan pengaruh error (e) maka didapatkan hasil untuk pengaruh error struktur $1\left(\mathrm{e}_{1}\right)$ sebesar 0,796 dan pengaruh error struktur $2\left(\mathrm{e}_{2}\right)$ sebesar 0,612. Selanjutnya akan dihitung koefisien determinasi total adalah sebagai berikut:

$$
\begin{aligned}
\mathrm{R}^{2}{ }_{\mathrm{m}} & =1-\left(\mathrm{e}_{1}\right)^{2}\left(\mathrm{e}_{2}\right)^{2} \ldots \ldots \ldots \ldots \ldots \\
& =1-(0,796)^{2}(0,612)^{2} \\
& =1-(0,633)(0,375) \\
& =1-0,237=0,763
\end{aligned}
$$

Pada perhitungan nilai koefisien determinasi total didapatkan sebesar 0,763, maka kesimpulannya adalah 76,3 persen variabel kinerja karyawan Single Fin Surf Shop, Cafe and Bar Kabupaten Badung .dipengaruhi oleh pengembangan karir, dan motivasi kerja, sedangkan sisanya 23,7 persen dipengaruhi oleh faktor lain yang tidak dimasukkan dalam model penelitian atau diluar model penelitian.

Perhitungan pengaruh secara langsung, pengaruh tidak langsung dan pengaruh total dari masing-masing persamaan struktural yang akan disajikan dalam Tabel 8 .berikut ini.

Tabel 8.

Pengaruh Langsung, Pengaruh Tidak Langsung Pengembangan Karir(X), Terhadap Motivasi Kerja (Z) dan Kinerja Karyawan (Y).

\begin{tabular}{lccc}
\hline \multicolumn{1}{c}{ Pengaruh variabel } & $\begin{array}{c}\text { Pengaruh } \\
\text { langsung }\end{array}$ & $\begin{array}{c}\text { Pengaruh tidak } \\
\text { langsung melalui } \mathbf{Z}\end{array}$ & Pengaruh Total \\
\hline $\mathrm{X} \rightarrow \mathrm{Z}$ & 0,606 & & 0,606 \\
$\mathrm{Z} \rightarrow \mathrm{Y}$ & 0,543 & & 0,543 \\
$\mathrm{X} \rightarrow \mathrm{Y}$ & 0,333 & 0,329 & 0,662 \\
\hline Sumber: Data diolah, 2019 & &
\end{tabular}

Pada Tabel 8. ditampilkan hasil ringkasan nilai masing-masing jalur pengaruh langsung dan tidak langsung antar variabel serta nilai error pada masing-masing persamaan struktural yang dihasilkan melalui teknik analisis jalur. Pada penelitian 
yang dilakukan di Single Fin Surf Shop, Cafe and Bar Kabupaten Badung tentang pengaruh pengembangan karir terhadap motivasi kerja, maka didapatkan hasil pengembangan karir memiliki pengaruh langsung terhadap motivasi kerja sebesar 0,606. Pada penelitian yang dilakukan di Single Fin Surf Shop, Cafe and Bar Kabupaten Badung tentang pengaruh motivasi kerja terhadap kinerja karyawan, maka didapatkan hasil motivasi kerja memiliki pengaruh langsung terhadap kinerja karyawan sebesar 0,543. Pada penelitian yang dilakukan di Single Fin Surf Shop, Cafe and Bar Kabupaten Badung tentang pengaruh pengembangan karir terhadap kinerja karyawan, maka didapatkan hasil pengembangan karir memiliki pengaruh langsung terhadap kinerja karyawan sebesar 0,333 .

Pada penelitian yang dilakukan Single Fin Surf Shop, Cafe and Bar Kabupaten Badung tentang peran motivasi kerja dalam memediasi pengaruh pengembangan karir terhadap kinerja karyawan, maka didapatkan hasil bahwa pengembangan karir memiliki pengaruh langsung dan tidak langsung melalui motivasi kerja terhadap kinerja karyawan dengan nilai koefisien masing-masing sebesar 0,333 dan 0,329, sehingga besaran pengaruh totalnya adalah 0,662.

Pengujian hipotesis mediasi dilakukan dengan metode VAF (Sholihin \& Ratmono, 2013) Prosedur ini dibagi menjadi dua bagian pengujian mediasi, pengaruh langsung harus signifikan. Kedua, setelah variabel mediasi dimasukkan ke dalam model, maka pengaruh tidak langsung (b x c) harus signifikan. Setiap jalur yaitu $b$ dan $\mathrm{c}$ harus signifikan untuk memenuhi kondisi ini.

Apabila ternyata pengaruh tidak langsung hasilnya signifikan, maka hal ini menunjukkan bahwa variabel pemediasi mampu menyerap atau mengurangi pengaruh langsung pada pengujian pertama. Ketiga, menghitung Variance Accounted For (VAF) dengan rumus pengaruh tidak langsung dibagi pengaruh total (pengaruh langsung ditambah pengaruh tidak langsung). VAF menjadi ukuran seberapa besar variabel pemediasi mampu menyerap pengaruh langsung yang sebelumnya signifikan dari model tanpa pemediasi.

VAF dapat dihitung dengan $(\mathrm{b} \times \mathrm{c}) /(\mathrm{a}+\mathrm{b} \times \mathrm{c})$ pengaruh langsung pengembangan karir Terhadap kinerja karyawan adalah sebesar 0,333 , pengaruh tidak langsung untuk pengembangan karir terhadap kinerja karyawan dengan motivasi kerja sebagai variabel mediasi adalah sebesar 0,329, nilai VAF $(0,329) /(0,333+0,329)$ yang didapatkan adalah 1,315 atau sebesar 131,5 persen, Nilai VAF lebih dari 80 persen, maka dapat dikategorikan sebagai pemediasi penuh (full mediation), maka dapat disimpulkan untuk efek mediasi yang dihasilkan untuk motivasi kerja memediasi pengaruh pengembangan karir terhadap kinerja karyawan adalah memediasi secara penuh (full mediation).

Hasil hipotesis dalam penelitian ini menunjukkan bahwa pengembangan karir memiliki pengaruh positif dan signifikan terhadap motivasi kerja. Ini ditunjukan oleh koefisien variabel pengembangan karir sebesar 0,606 yang signifikan dengan nilai signifikan 0,000 lebih kecil dari $\alpha$ sebesar 0,05 dengan kata lain semakin baik pengembangan karir yang ada di Single Fin Surf Shop, Cafe and Bar, maka semakin tinggi tingkat motivasi kerja Single Fin Surf Shop, Cafe and Bar Kabupaten Badung. Sehingga hipotesis pertama diterima.

Hal ini sejalan dengan hasil penelitian yang dilakukan oleh Mahmud et al. (2018), Lisdiani \& Ngatno (2017), Hannekam (2016), Bapiri \& Alizad (2015), 
Supranowo (2017), Pillay (2015), Anthony \& Weide (2015) menyatakan bahwa pengembangan karir berpengaruh positif dan signifikan terhadap motivasi kerja karyawan.

Hasil hipotesis dalam penelitian ini menunjukkan bahwa pengembangan karir berpengaruh positif dan signifikan terhadap kinerja karyawan. Ini ditunjukan oleh koefisien variabel pengembangan karir sebesar 0,333 yang signifikan dengan nilai signifikan 0,000 lebih kecil dari $\alpha$ sebesar 0,05 dengan kata lain semakin meningkat pengembangan karir maka kinerja karyawan Single Fin Surf Shop, Cafe and Bar Kabupaten Badung akan semakin meningkat. Sehingga hipotesis kedua diterima.

Hal ini sejalan dengan hasil penelitian yang dilakukan oleh Nasution et al., (2018), Purwanto dkk. (2017), Rosmadi (2018), Kurniawan et al., (2017), Charity (2015),Parerung (2014), Napitupulu (2017) bahwa pengembangan karir berpengaruh positif dan signifikan terhadap kinerja karyawan.

Hasil hipotesis dalam penelitian ini menunjukkan bahwa motivasi kerja memiliki pengaruh positif dan signifikan terhadap kinerja karyawan. Ini ditunjukan oleh koefisien variabel pengembangan karir sebesar 0,543 yang signifikan dengan nilai signifikan 0,000 lebih kecil dari $\alpha$ sebesar 0,05 dengan kata lain apabila motivasi kerja meningkat maka kinerja karyawan Single Fin Surf Shop, Cafe and Bar Kabupaten Badung akan semakin meningkat. Sehingga hipotesis ketiga diterima.

Hasil penelitian ini sesuai dengan penelitian yang dilakukan oleh Larasati \& Gilang (2014), Ayundasari et al., (2017) ,Theodoran (2015), Ibrahim (2017), Bismantara (2017) menyatakan bahwa motivasi kerja berpengaruh positif dan signifikan terhadap kinerja karyawan.

Hasil hipotesis dalam penelitian ini menunjukkan bahwa pengembangan karir berpengaruh positif dan signifikan terhadap kinerja karyawan Single Fin Surf Shop, Cafe and Bar Kabupaten Badung dengan mediasi motivasi kerja. Berdasarkan perhitungan Sobel test diproleh nilai $\mathrm{Z}$ adalah 4,759. Nilai 4,759 lebih besar dibandingkan 1,96 sehingga motivasi kerja merupakan variabel mediasi pengaruh antara pengembangan karir terhadap kinerja karyawan Single Fin Surf Shop, Cafe and Bar Kabupaten Badung, Sehingga hipotesis keempat diterima.

Hasil penelitian ini sejalan dengan hasil penelitian yang dilakukan oleh Dewi \& Utama (2016), Umar (2015), Oduma et al. (2014), Balbed \& Sintasih (2019), (Sari, \& Sriathi (2019) menunjukkan bahwa motivasi kerja berpengaruh positif terhadap kinerja karyawan serta mampu memediasi pengaruh pengembangan karir terhadap kinerja karyawan. Hasil ini menyatakan bahwa semakin baik pengembangan karir diperusahaan semakin tinggi motivasi kerja karyawan, dan semakin tinggi motivasi kerja karyawan akan semakin tinggi kinerja karyawan.

Implikasi teoritis dari hasil penelitin ini memberikan bukti pada pengembangan ilmu perilaku keorganisasian dan sumber daya manusia khususnya mengenai pengembangan karir, motivasi kerja dan kinerja karyawan. Selain itu hasil penelitian ini secara praktis dapat menjadi salah satu acuan bagi peneliti lainnnya yang ingin meneliti mengenai pengembangan karir, motivasi kerja dan kinerja karyawan. Secara teoritis penelitian ini juga memberikan pemahaman bahwa pengembangan karir dan motivasi kerja secara nyata dapat meningkatkan kinerja karyawan, ketika pengembangan karir yang diperoleh oleh karyawan 
meningkatkan motivasi kerja, maka motivasi kerja yang dirasakan oleh karyawan menjadi semakin kuat sehingga berpotensi meningkatkan kinerja karyawan.

Terdapat keterbatasan yang mempengaruhi kondisi dari penelitian yang dilakukan. Adapun keterbatasan dalam penelitian ini yaitu faktor-faktor yang mempengaruhi kinerja karyawan dalam penelitian ini terdiri dari 2 variabel yaitu pengembangan karir dan motvasi kerja, sedangkan masih banyak faktor lain yang mempengaruhi kinerja karyawan. Selanjutnya mengenai keterbatasan penelitian dengan menggunakan kuesioner yaitu jawaban dari responden terkadang kurang menunjukkan keadaan yang sesungguhnya.

\section{SIMPULAN}

Pengembangan karir berpengaruh positif dan signifikan terhadap motivasi kerja Single Fin Surf Shop, Cafe and Bar Kabupaten Badung. Hal ini menunjukkan bahwa jika pengembangan karir baik maka semakin tinggi motivasi kerja karyawan.Pengembangan karir berpengaruh positif dan signifikan terhadap kinerja karyawan Single Fin Surf Shop, Cafe and Bar Kabupaten Badung. Hal ini menunjukkan bahwa jika pengembangan karir baik maka kinerja karyawan semakin baik. Motivasi kerja berpengaruh positif dan signifikan terhadap kinerja karyawan Single Fin Surf Shop, Cafe and Bar Kabupaten Badung. Hal ini menunjukkan bahwa semakin tinggi motivasi kerja karyawan maka kinerja karyawan semakin baik. Motivasi kerja berpengaruh positif dan signifikan memediasi pengaruh pengembangan karir terhadap kinerja karyawan. Hal ini menunjukkan bahwa pengembangan karir memberikan dampak yang signifikan terhadap kinerja karyawan jika di mediasi oleh motivasi, yang berarti bahwa kinerja karyawan sangat bergantung pada tingkat motivasi dari karyawan tersebut dan juga tingkat pengembangan karir karyawan.

Indikator yang memiliki rata-rata terendah dari variabel pengembangan karir adalah saya merasa atasan selalu mendukung pengembangan karir karyawan. Dari indikator tersebut sebaiknya atasan memberikan dukungan kepada karyawan guna untuk memproleh jabatan yang lebih tinggi dari sebelumnya. Indikator yang memiliki rata-rata terendah dari variabel motivasi kerja adalah dalam bekerja saya selalu menaati peraturan yang diteapkan oleh perusahaan.

Dari indikator tersebut sebaiknya pihak perusahaan lebih memertegas peraturan yang ada diperusahaan agar karyawan tidak melanggar peraturan yang ditetapkan oleh perusahaan. Indikator yang memiliki rata-rata terendah dari variabel kinerja karyawan adalah saya bisa memisahkan masalah utama dari masalah lainnya di tempat kerja. Dari indikator tersebut sebaiknya karyawan bisa memprioritaskan masalah mana yang terlebih dahulu untuk diselesaikan agar nantinya karyawan bisa menyelesaikan pekerjaan dengan baik sehingga tidak ada dampak buruk terhadap kinerja karyawan.

\section{REFERENSI}

Anthony, P. J., \& Weide, J. (2015). Motivation and Career-Development Training Programs: Use of Regulatory Focus to Determine Program Effectiveness. Use 
of Regulatory Focus to Determine Program Effectiveness., 5(2), 24-33. https://doi.org/10.1377/hlthaff.2013.0625

Ayundasari, D. Y., Sudiro, A., \& Wirawan, D. (2017). Improving Employee Performance Through Work Motivation and Self Efficacy Mediated by Job Satisfaction. Journal of Applied Management, 3(4).

Balbed, Ammar., \& S. D. K. (2019). Pengaruh Pengembangan Karir Terhadap Kinerja Karyawan Melalui Pemdiasi Motivasi Kerja Karyawan. 8(7).

Bapiri, S., \& Alizad, R. . (2015). Evaluation Of The Effect of Career Development on Occupational Motivation in Employees Of The Sepah Bank in Kermanshah Country. 18(1), 633-642.

Baroroh, A. (2012). Pengaruh Pengembangan Karir dan Motivasi terhadap Kinerja dengan Kepuasan Kerja sebagai Variabel Intervening (Studi Kasus Pada Politeknik Ilmu Pelayaran Semarang). Jurnal Analisis Manajemen, 5(1), 6580.

Bismantara. (2017). Pengaruh Pemberian Motivasi dan Pelatihan Kerja terhadap Kinerja Karyawan. Jurnal Kewirausahaan, 3(2), 1-14.

Budianto, A. A. T., \& Katini, A. (2015). Pengaruh Lingkungan Kerja Terhadap Kinerja Pegawai Pada Pt Perusahaan Gas Negara (Persero) Tbk Sbu Distribusi Wilayah I Jakarta. Jurnal Ilmiah Prodi Manajemen Universitas Pamulang, $3(1), 100-124$.

Cederyana, L., \& Supriyati, Y. (2018). Influence of Work Discipline Career Development and Job Satisfaction on Employee Perfomance Directorate Generl Research Technology and Higher Education. International Journal Of Scientific Research And Management, 6(2), 87-96.

Charity, B. C. (2015a). Effect of Training and Career Development on Employee Performance: A Case of KCB Branches in The North Rift Region, Kenya. Kenya. International Journal of Advanced Research in Management and Social Science, 4(5), 2278-6236. https://doi.org/10.1377/hlthaff.2013.0625

Charity, B. C. (2015b). Effect of Training and Career Development on Employee Performance: A Case of KCB Branches in The North Rift Region, Kenya. International Journal of Advanced Research in Management and Social Science, 4(5), 38-49.

Dewi, N. L. P. A. A., \& Utama, I. W. M. (2016). Pengaruh Pengembangan Karir Terhadap Kinerja Karyawan Melalui Mediasi Motivasi Kerja pada Karya Mas Art Gallery. E-Jurnal Manajemen Unudurnal Manajemen Unud, 5(9), 23028912.

Elqadri, Z. M., Priyono, Suci, R. P., \& Chandra, T. (2015). Effect of Leadership 
Style, Motivation, and Giving Incentives on the Performance of EmployeesPT. Kurnia Wijaya Various Industries. International Education Studies, 8(10), 183-192. https://doi.org/10.5539/ies.v8n10p183

Hakim, R. B. (2014). Manajemen dan Evaluasi Kinerja Karyawan (Edisi Pert). Jakarta: Aswaja Presindo.

Hannekam, S. (2016). Competencies of Older Workers and Its Influence on Career Success and Job Satisfaction. The International Journal, 38.

Ibrahim, A. A. (2017). The Effect of Motivation on Emplyee Perfomance: Case Study in Hormuud Company in Mogadishu Somalia. International Journal of Development Research. 7(1):17009-17016., 7(1), 24-25. https://doi.org/10.1002/ejsp.2570

Kaymz, K. (2011). Performance feedback: individual based reflections and the effect on motivation. Business and Economics Research Journal, 2(4), 115134.

Kudsi, M. R., Riadi, S. S., \& AS, D. L. (2017). Pengaruh pengembangan karir dan Sistem Insentif terhadap Kinerja Karyawan. Jurnal Manajemen, 9(2), 85-93. https://doi.org/10.29264/jmmn.v9i2.1977

Kuranchie-Mensah, E. B., \& Amponsah Tawiah, K. (2016). Employee Motivation and Work Performance: A Comparative Study of Mining Companies in Ghana Elizabeth. Journal of Industrial Engineering and Management, 21(1-12), 281-289. https://doi.org/10.1524/auto.1973.21.112.281

Kurniawan, A., Yunus, M., \& Majid, M. S. A. (2017). Pengaruh Kompensasi dan Pengembangan Karir terhadap Motivasi Serta Dampaknya Pada Kinerja Karyawan PT. Bank Syariah Mandiri Cabang Banda Aceh. Jurnal Manajemen Dan Inovasi, 8(2), 119-133.

Larasati, S., \& Gilang, A. (2014). Pengaruh Motivasi Kerja terhadap Kinerja Karyawan Wilayah Telkom Jabar Barat Utara (Witel Bekasi). Ilmu Administrasi Bisnis, 201-213. https://doi.org/10.29244/jmo.v5i3.12167

Lisdiani, V., \& Ngatno. (2017). Pengaruh Pengembangan Karir terhadap Kepuasan Kerja Karyawan Melalui Motivasi Kerja Sebagai Variabel Intervening (Studi Kasus Pada Hotel Grasia Semarang). Diponegoro Journal of Social and Political Sciencet, 1-8.

Mahmud, A., Abbas, B., \& Rahmatia, R. (2018). Pengaruh Gaya Kepemimpinan Situasional terhadap Pengembangan Karir yang di Mediasi oleh Motivasi pada Bidang Persidangan Sekretariat DPRD Provinsi Sulawesi Tenggara. Journal of Economic and Business, 1(79), 1-23. Retrieved from http://journal.stie66ac.id/index.php/sigmajob 
Muogbo, U. S. (2013). The Impact of Employee Motivation on Organisational Performance ( A Study of Some Selected Firms In Anambra State Nigeria ). International Journal Of Engineering and Science (IJES), 2(7), 70-80.

Napitupulu, S. (2017). The Impact of Career Development on Employee Perfomance ( A Study of Some Selected Firms in Anambra State Nigeria). 2(7), 70-80.

Nasution, F. N., Mariatin, E., \& Zahreni, S. (2018). The Influence of Career Development and Organizational Culture on Employee Performance. International Journal of Scientific Research and Management, 6(01), 57-65. https://doi.org/10.18535/ijsrm/v6i1.el09

Nkechi, P. A. J., \& Dialoke, I. (2017). Effects of Career Growth on Employees Performance: A Study of Non-Academic Staff of Michael Okpara University of Agriculture Umudike Abia State, Nigeria. Singaporean Journal of Business Economics and Management Studies, 5(7), 8-18. https://doi.org/10.12816/0037246

Nurcahyani, N. M., \& Adnyani, I. G. A. D. (2016). Pengaruh Kompensasi dan Motivasi Terhadap Kinerja Karyawan Dengan Kepuasan Kerja Sebagai Variabel Intervening. E-Jurnal Manajemen Unud, 5(1), 500-532.

Oduma, Caroline, \& Susan, W. (2014). Influence of Career Development on Employee Performance in The Public University, a Case of Kenyatta University. International Journal of Social Sciences Management and Entrepreneurship, 1(2), 1-16.

Omolo, P. A. (2015). Effect of motivation on employee performance of commercial banks in Kenya: A case study of Kenya Commercial Bank in Migori County. International Journal of Human Resource Studies, 5(2), 87-103. https://doi.org/10.5296/ijhrs.v5i2.7504

Parerung, A. (2014). Disiplin Kompensasi, dan Pengembangan Karir Pengaruhnya Terhadap Kinerja Pada Badan Lingkungan Hidup Provinsi Sulawesi Selatan. Journal of Chemical Information and Modeling, 2(4), 688-696. https://doi.org/10.1017/CBO9781107415324.004

Pillay, N. (2015). The Relation Between Career Development and Staff Motivation in The South African Petroleum Sector: A Case Study Of A Durban Refinery. Arabian Journal of Business and Management Review (Nigerian Chapter), 3(2), 1-51. https://doi.org/10.1145/3132847.3132886

Pratiwi, P. Y. A. (2017). Pengaruh Lingkungan Kerja dan Perkembangan Karier terhadap Retensi Karyawan Pada Hotel Santika Nusa Dua Bali. E-Jurnal Manajemen Unud, 6(3).

Purwanto S. Katidjan, Suharno Pawirosumarto, dan A. I. (2017). Pengaruh Kompensasi, Pengembangan Karir dan Komunikasi terhadap Kinerja Karyawan. Jurnal Ilmiah Manajemen, 7(3), 429-446. 
Rosmadi, M. L. N. (2018). Pengaruh pelatihan, disiplin, dan pengembangan karir terhadap kinerja karyawan. Jurnal Bisnis Manajemen Dan Informatika, 14(3), 205-216.

Sari, Ni Putu. S. K,. \& Sriathi, A. A. A. (2019). Peran Motivasi Kerja Memediasi Pengaruh Pengembangan Karir Terhadap Kinerja Karyawan Fairmont Sanur Beach Hotel. E-Jurnal Manajemen, 8(8), 75-84. https://doi.org/.1037//00332909.I26.1.78

Sari, N. N. (2016). Pengaruh Pengembangan Karir terhadap Kinerja Karyawan PT Pln (Persero) Wilayah Kalimantan Utara Sektor Pembangkit Mahakam Samarinda. EJournal Administrasi Bisnis, 4(2), 620-630.

Shahzadi, I., Javed, A., Pirzada, S. S., Nasreen, S., \& Khanam, F. (2014). Impact of Employee Motivation on Employee Performance. European Journal of Business and Management, 6(23), 159-167.

Sholihin, M., \& Ratmono, D. (2013). Analisis SEM-PLS dengan WarpPLS 3.0 untuk Hubungan Nonlinear dalam Penelitian Sosial dan Bisnis, Penerbit Andi Yogyakarta. 2013. 2013.

Supranowo. (2017). The Influence of Working Environment Conditions, Compensation and Career Development on Employees' Working Motivation at an Indonesian Bank. Expert Journal of Business and Management, 5(2), $142-148$.

Susilo, C. I., Prasetyo, I., \& Riswati, F. (2018). Pengaruh Budaya Organisasi dan Pengembangan Karir terhadap Kepuasan Kerja Prajurit Melalui Motivasi Kerja di Satuan Kapal Amfibi Koarmatim. Jurnal Manajerial Bisnis, 1(2), $138-153$.

Theodora, O. (2015). Pengaruh Motivasi Kerja terhadap Kinerja Karyawan PT Sejahtera Motor Gemilang. Agora, 3(2), 187-195.

Tran, T. . Le, \& Chiou-shu, J. . (2015). Factors Affecting Employee PErformance Evidence From PEtrovietnam Engineering Concultacy. J.S.C Human Resource Management Journal, 43.

Umar, A. (2015). The Effect of Motivation and Career Development Against Employees Performance and Job Satisfaction of the Governor Office South Sulawesi Province, Indonesia. International Journal of Management Sciences, 5(9), 628-638.

Winda Annisa Putri. (2019). Pengaruh Pengembangan Karier Terhadap Motivasi dan Dampaknya Terhadap Kinerja Karyawan (Studi Kasus di PT. Barata Indonesia (Persero) Gresik). Jurnal Ilmu Manajemen, 7(2), 1-10. 
Ni Komang Sisi Sania Natalia, Pengaruh Motivasi Kerja...

Zameer, H., \& Shehzad, A. (2014). The Impact of The Motivation on The Employees Performance in Baverage Industry of Pakistan. International Journal of Academic Research in Accounting, Finance and Management Science, 4(1). 